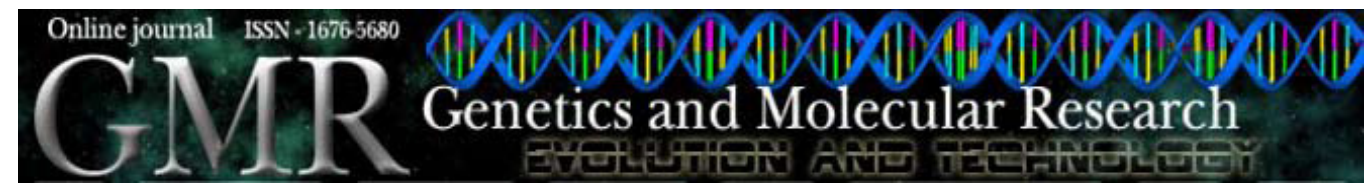

\title{
Novel exon nucleotide deletion causes adrenoleukodystrophy in a Brazilian family
}

\author{
E.R. Valadares ${ }^{2,4 *}$, A.L.C. Trindade ${ }^{1 *}$, L.R. Oliveira ${ }^{3,4}$, R.R. Arantes ${ }^{4}$, \\ M.V. Daker ${ }^{4}$, B.M. Viana ${ }^{4}$, V.G. Haase ${ }^{5}$, L.B. Jardim ${ }^{6}$, G.C. Lopes ${ }^{1}$ \\ and A.L.B. Godard ${ }^{1}$ \\ ${ }^{1}$ Laboratório de Genética Animal e Humana, \\ Instituto de Ciências Biológicas, Departamento de Biologia Geral, \\ Universidade Federal de Minas Gerais, Belo Horizonte, MG, Brasil \\ ${ }^{2}$ Departamento de Propedêutica Complementar, \\ Faculdade de Medicina, Universidade Federal de Minas Gerais, \\ Belo Horizonte, MG, Brasil \\ ${ }^{3}$ Departamento de Pediatria, Faculdade de Medicina, \\ Universidade Federal de Minas Gerais, Belo Horizonte, MG, Brasil \\ ${ }^{4}$ Hospital das Clínicas, Faculdade de Medicina, \\ Universidade Federal de Minas Gerais, Belo Horizonte, MG, Brasil \\ ${ }^{5}$ Departamento de Psicologia, Faculdade de Filosofia e Ciências Humanas, \\ Universidade Federal de Minas Gerais, Belo Horizonte, MG, Brasil \\ ${ }^{6}$ Hospital de Clínicas de Porto Alegre, Porto Alegre, RS, Brasil \\ *These authors contributed equally to this study. \\ Corresponding author: A.L.B. Godard \\ E-mail: brunialt@ufmg.br
}

Genet. Mol. Res. 10 (1): 65-74 (2011)

Received July 13, 2010

Accepted November 3, 2010

Published January 18, 2011

DOI 10.4238/vol10-1gmr975

ABSTRACT. Adrenoleukodystrophy is a neurodegenerative X-linked recessive disorder. It is characterized by abnormal function of peroxisomes, which leads to an accumulation of very long-chain fatty acids in plasma and tissues, especially in the cortex of adrenal glands and white matter of the central nervous system, causing demyelinating disease and adrenocortical insufficiency (Addison's disease). It is caused by a mutation in the ABCD1 gene (ATP-binding cassette, subfamily D, member 1), which encodes the 
protein adrenoleukodystrophy that is involved in the transport of fatty acids into the peroxisome for degradation. Variable expression has been recognized in families of patients who have this disease. A Brazilian family from Minas Gerais State, Brazil, was studied. The proband is an adult living in Minas Gerais State, Brazil; he had adrenomyeloneuropathy, adrenocortical insufficiency and a stable cerebral form. DNA was extracted from a blood sample and was sequenced to identify the mutation. The patient's exons were cloned for confirmation. A new mutation was found in exon 5 of the ABCD1 gene (c.1430delA), as well as a single-nucleotide polymorphism in exon 6 . The mutation causes a frame shift, resulting in a truncated protein with almost total absence of the ATP binding domain.

Key words: Adrenoleukodystrophy; X-linked; $\mathrm{ABCD} 1$ gene; Molecular diagnosis; Addison's disease; $\mathrm{ABC}$ transporters

\section{INTRODUCTION}

$\mathrm{X}$-linked adrenoleukodystrophy (X-ALD - MIM \#300100) is a peroxisomal, progressive and neurodegenerative disorder that affects the cortex of adrenal glands and the white matter of the nervous system. It was first reported in Germany by Siemerling and Creutzfeldt (1923) as "Bronzekrankheit und Sklerosiende Encephalites", because of the unique combination of primary adrenocortical insufficiency (Addison's disease) and cerebral inflammatory demyelinization. Blaw (1970) introduced the name "adrenoleukodystrophy". Igarashi et al. (1976) and Moser et al. (1981) found large amounts of cholesterol esters with saturated very long-chain fatty acids (VLCFA) in extracts of brain, adrenal tissue, fibroblasts and blood cells, and especially in the plasma of patients with X-ALD, a discovery of crucial importance for the identification of patients (Kemp and Wanders, 2007). Plasma VLCFA is the best initial biomarker for X-ALD to date.

This disorder is $\mathrm{X}$-linked recessive and has the highest frequency among the group of peroxisomal diseases (Kemp and Wanders, 2007). The minimum estimated incidence in the U.S. ranges from 1:42,000 for homozygous males to 1:16,800 for both homozygous males and heterozygous females (Bezman et al., 2001). In South Brazil, the minimum estimated incidence for homozygous males is 1:35,000 (Jardim et al., 2010).

This disease is related to changes in the ATP-binding cassette, subfamily D, member 1 gene (ABCD1 - MIM \#300371), identified by positional cloning techniques by Mosser et al., in 1993. This gene is located on chromosome Xq28 and consists of 10 exons with a total of 19,894 bp and a coding sequence of $3664 \mathrm{bp}$. It encodes a transporter protein of the adenosine triphosphate-binding cassette family (Pan et al., 2005), which consists of 745 amino acids and is located in the peroxisome membrane; it is called adrenoleukodystrophy protein (ALDP - accession No. NP_000024 in the NCBI).

The $\mathrm{ABC}$ transporters are ATPases and have the important role of transporting various substrates such as proteins, amino acids and inorganic ions across membranes (Lachtermacher et al., 2000). Mutations in ALDP lead to the accumulation of saturated VLCFA, with more than 22 carbons, mainly with 26 carbons (hexacosanoic acid), due to impairment of peroxisomal $\beta$-oxidation of fatty acids (van Roermund et al., 2008). This biochemical process induces the shortening of various fatty acid chains, including VLCFA, and is accomplished through four sequential steps of 
dehydrogenation, hydration, further dehydrogenation, and thiolytic cleavage. As a result, the first two carbon atoms of the acyl-CoA fatty ester are released as acetyl-CoA, leaving one shorter acylCoA ester that can undergo new processes of $\beta$-oxidation (Kemp and Wanders, 2007).

Kemp and Wanders (2007) stated that the oxidation of C24:6 omega-3 involves the same set of enzymes as the oxidation of $\mathrm{C} 26: 0$, but despite that, the first oxidation is completely normal in fibroblasts from patients with X-ALD. This suggests that the defect in the oxidation of $\mathrm{C} 26: 0$ is not due to an abnormality in peroxisomal $\beta$-oxidation itself. Moreover, it suggests that ALDP is involved with the import of VLCFA into the peroxisome, although its function is not completely clear (van Roermund et al., 2008).

Diagnosis by measurement of VLCFA in plasma of patients with X-ALD is achieved when high concentrations of hexanoic acid (C26:0) and increased ratios of hexanoic to docosanoic acid (C26:0/C22:0) and/or tetracosanoic to docosanoic acid (C24:0/C22:0) are found (Moser et al., 1999). Although this test is highly reliable for diagnosis in males, with only $0.1 \%$ affected males showing VLCFA levels in the normal range (Lachtermacher et al., 2000), there is a rate of $15-20 \%$ falsenegatives in obligate female carriers (Boehm et al., 1999). Thus, normal plasma levels of VLCFA do not exclude the possibility of a subject being X-ALD heterozygous (Kemp and Wanders, 2007). This observation, together with the existence of allelic heterogeneity and a large number of different mutations, show that genetic testing of all exons of individuals is the most reliable way to determine the diagnosis in each family. This effective detection of mutations is fundamental in determining unequivocally the genetic status of individuals at risk (Lachtermacher et al., 2000).

Long-chain fatty acids have a long uncharged carbon chain (hydrophobic tail) and a charged carboxyl chain (hydrophilic). Its accumulation allows the hydrophobic tails to interact with the components of the myelin sheath, resulting in local immune reaction causing the dissolution of the latter. This leads to demyelination, which gradually hinders the conduction of nerve impulses. As a result, the nervous system becomes less efficient (Grosko and Ferreira, 2006).

The clinical manifestation of X-linked adrenoleukodystrophy disease is highly variable, and many authors have already shown that there is no correlation between clinical phenotype, VLCFA levels and genotype, and that the degree of loss of function of ALDP is not related to disease severity (Moser and Moser, 1996; Pan et al., 2005). This lack of correlations suggests that the observed variation can be caused by an autosomal modifier gene (Smith et al., 1991; Moser et al., 1995) or by other factors not yet identified (Korenke et al., 1996). Seven different phenotypes were described for male patients and five for female patients (Xlinked Adrenoleukodystrophy Database - http://www.X-ald.nl/).

The phenotypes can be subdivided into four main categories: cerebral inflammatory, adrenomyeloneuropathy (AMN), Addison-only, and asymptomatic. Within a family, it is more common to find diverse phenotypes than identical ones (Moser et al., 2007). Addison-only occurs between 2 years of age and adulthood, without nervous system involvement, although most of these patients later show some neurological signs. Childhood cerebral adrenoleukodystrophy occurs in $35 \%$ of patients and is the most severe and devastating phenotype. It commonly manifests between the ages of 4 and 8 years, causing attention deficit, followed by progressive impairment of cognition, behavior, vision, hearing, and motor function. Death often occurs 2 to 4 years after the onset of symptoms due to complications such as pneumonia. AMN is the most common form of the disease and is characterized by slow progression with initial symptoms limited to the spinal cord and the peripheral nerves, the major sites of demyelination (van Geel et al., 1996). Most often, it manifests at early ages, i.e., at around 20 years or in late twenties as progressive paresis, sphincter disturbance and sexual dysfunc- 
tion (Moser et al., 2001). About $65 \%$ of patients with AMN have adrenal gland insufficiency, which can remain as the only symptom for 5 to 15 years (van Geel et al., 1994). All symptomatic patients worsen with the passage of decades (Moser et al., 2001). Approximately 19\% of patients with AMN develop cerebral demyelinating changes, and when it appears, they show a disease development similar to that observed in childhood forms (van Geel et al., 2001).

Approximately $50 \%$ of female carriers develop an AMN-like phenotype (Moser et al., 2001), but only a few of them show abnormalities on magnetic resonance imaging (MRI) of the brain and spinal cord (van der Knaap and Valk, 2005). Adrenal cortical insufficiency is rarely observed in ALD heterozygotes, but a subclinical decrease in glucocorticoid reserves may be present in the majority of these women (El-Deiry, 1997).

Therapeutic options for X-ALD vary with the development of the phenotype (Peters et al., 2004; Mahmood et al., 2005; Moser, 2006) and, in some cases, can change the natural course of the disease.

This study is part of a larger project, whose aim is the investigation of degenerative and metabolic diseases of the nervous system. A significant number of people may benefit from this project, as it covers diagnosis, monitoring and genetic counseling.

The main objective of this research was to identify the mutation causing adrenoleukodystrophy in the family studied.

\section{MATERIAL AND METHODS}

\section{Subjects}

The study included 33 individuals of a known family with adult manifestation of the disease, 14 males and 19 females. After obtaining the patients' informed consent (ETIC 337/06), clinical and neurological assessments were performed and blood samples $(10 \mathrm{~mL})$ were collected.

\section{Molecular controls}

DNA from 50 individuals, including Brazilians (9 females and 9 males), Asians (10 and 6) and Hispanics (10 and 6), were used as controls. Samples were obtained from the SNP500 Cancer Panel of the Institute Couriel.

\section{Extraction of DNA from whole blood}

Genomic DNA was extracted from $5 \mathrm{~mL}$ peripheral blood according to a standard protocol using lysis buffer (10 mM Tris-HCl, $\mathrm{pH} 8.0,2 \mathrm{mM}$ EDTA, $\mathrm{pH} 8.2$, and 10\% SDS) and proteinase $\mathrm{K}(20 \mathrm{mg} / \mathrm{mL})$. Pellets were washed with $70 \%$ ethanol and dissolved in TE solution (Miller et al., 1988). The concentration of extracted DNA was determined by spectrophotometry at $260 \mathrm{~nm}$.

\section{Molecular analysis}

First, the exons of the $\mathrm{ABCD} 1$ gene and the splicing sites were amplified from the genomic DNA using polymerase chain reaction (PCR). In order to obtain the primer sequences used in the experiments, three articles were used as reference: Boehm et al., 1999; Montagna et al., 
2005, and Pan et al., 2005. Using softwares to design and analyze primers - Primer3 (http://frodo. wi.mit.edu/primer3/) and NetPrimer (http://www.premierbiosoft.com/netprimer/netprlaunch/netprlaunch.html) - we selected the best primer pairs for this research.

Due to the large size of exon 1 (1299 bp), three pairs of primers overlapping each other were utilized to cover the whole length. Owing to the paralogous sequences of exons $7,8,9$, and 10 in the autosomes 2p11, 10p11, 16p11, and 22q11 (Eichler et al., 1997), we decided to first preamplify these exons all together and subsequently amplify them individually from the fragment obtained. However, a pre-amplification containing exon 7 was not feasible due to the size of the intron between exons 7 and 8 (2267 bp). Thus, the pre-amplification consisted of exons 8, 9 and 10 .

To verify if the amplified fragments corresponded to the correct amplicon, the sequences were compared with the reference sequence, and $100 \%$ identity was obtained. The sequence of the ABCD1 gene differs from its autosomal paralogous sequence in various positions within the amplified fragments. Thus, confirmation of the amplicons' specificity can be obtained by analyzing these few variant nucleotides (Boehm et al., 1999).

In order to identify the mutated fragment, single-strand conformation polymorphism (SSCP) analysis was applied to the amplification products of each exon of the family members and control individuals. The fragments that exhibited a different migration pattern in the gel between individuals from the family and control individuals, and those that could not be correctly analyzed with SSCP (data not shown) were sequenced with the aim of identifying the mutation causing the disease.

For sequencing, samples were purified from 1\% agarose gels after electrophoresis of PCR products, using the Promega Wizard ${ }^{\mathbb{B}}$ SV Gel and PCR Clean-up System kit. Sequencing was performed in an ABI 3130 Genetic Analyzer using Big Dye ${ }^{\circledR}$ Terminator v3.1 Cycle Sequencing Kit, both manufactured by Applied Biosystems, according to the protocol suggested by the manufacturer. Both strands of the samples were sequenced, forward and reverse directions. The sequences obtained were analyzed using Sequence Scanner v1.0 (Applied Biosystems) and CodonCode Aligner (http://www.codoncode.com/aligner/) softwares. Mutational analyses were performed using the genome sequence of normal humans, aside from databases, as reference. At Ensembl Database, www.ensembl.org, the accession number of the gene is ENSG00000101986, and at GenBank, www.ncbi.nlm.nih.gov/gene/, the GeneID is 215, RefSeqGene: NG_009022.1. Sequences of both databases were compared using BLAST (http:// blast.ncbi.nlm.nih.gov/Blast.cgi) to ensure the accuracy of the reference used.

To confirm the mutation, gene fragments containing the possible alteration were cloned from a few individuals of the family and control samples. Cloning was performed on PCR $^{\circledR}$ II-TOPO ${ }^{\circledR}$ plasmid using TOPO TA Cloning Kit, as recommended by the manufacturer (Invitrogen ${ }^{\mathrm{TM}}$ Life Technologies, Carlsbad, CA, USA), and both alleles were sequenced.

\section{RESULTS}

\section{Subjects}

The proband of this study is now 39 years old. His diagnosis of adrenomyeloneuropathy was established in Italy, when he was 26 , three years after the first symptoms of spastic paraparesis. The results of his VLCFA levels determined at Laboratorio de Biochimica e Genetica del Sistema Nervoso, Milano, Italy, were: C26:0 $=3.72 \mu \mathrm{M}$ (reference $<1.50$ ), C26:0/C22:0 x 1000 $=67$ (reference $<28$ ), C24:0/C22:0 x 1000 = 1626 (reference <1100). Later, he manifested Addison's disease. 
Since age 31, his MRI has shown a pattern of atrophy of the brainstem and symmetrical parenchymal lesions with hyperintense signal on T2 and "flair" at the cortico-spinal tracts, with unchanged Loes score (Loes et al., 2003) of 4 . The disease has progressed slowly and he can walk with braces. He uses daily oral doses of $20 \mathrm{mg}$ lovastatin and $10 \mathrm{mg}$ prednisone.

One brother of the proband manifested the disease at 28 years and died at 32, without diagnosis. One 54-year-old sister has mild hemiparesis on the right side, with normal MRI of brain and spinal cord, and normal adrenal function. She will continue to be under observation, since a somatosensory-evoked potential has not been available to support AMN. One 54-year-old cousin presented changes in behavior, urinary urgency, loss of short-term memory at age 51 and was diagnosed at age 53 with Addison's disease, slowly progressive adult cerebral form and possible AMN. Another cousin, not seen by this research group, now 48 years old, started at age 43 showing signs of depression and aggressiveness, followed by paraparesis and difficulty with speaking and swallowing.

\section{Molecular diagnosis}

All 10 exons were analyzed. In a male control, a previously described single-nucleotide polymorphism (SNP) was found in exon 6, consisting of an adenine replacing a guanine - c. $1548 \mathrm{G}>\mathrm{A}(\mathrm{ATG}=387, \mathrm{c} .1934 \mathrm{G}>\mathrm{A})$. This transition does not alter the translation of codon 516 for leucine (CTG $>$ CTA), p.Leu516Leu (Fanen et al., 1994). The identification number of the SNP in dbSNP, NCBI, is rs \#41314153 (Figure 1).

A

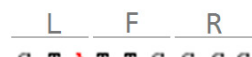

Male control
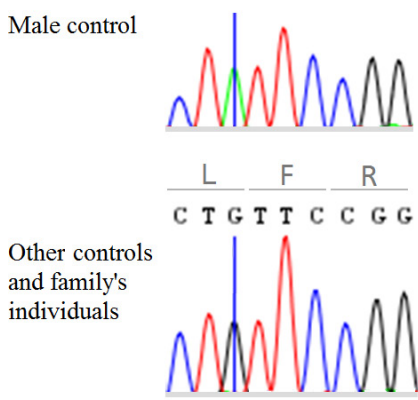

B

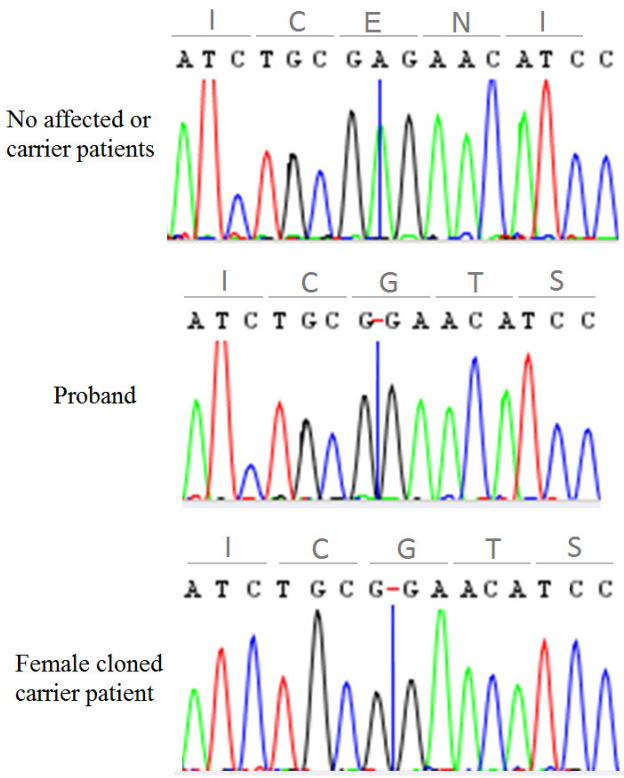

Figure 1. Analysis of the sequences of the $\mathrm{ABCD} 1$ gene of members of the family and controls. A. Electropherogram of a male control showing the polymorphism in exon 6, at position 1934, of the coding sequence of the ABCD1 gene (c.1934G $>$ A), which maintains the translation for a leucine. B. Electropherograms showing the mutation found at position 1430, in exon 5, from the coding sequence of the ABCD1 gene (c.1430delA) of members of the family studied. The adenine deletion results in a frame shift and, consequently, in a truncated protein. 
The mutation within the family was found in exon 5 (Figure 1) and consists of an adenine deletion at position 37 of the exon, c. $1430 \mathrm{del} A(\mathrm{ATG}=387$, c.1816delA), at codon 477, which encodes glutamate (p.Glu477GlyfsX80). The nomenclature used to indicate the alterations follows the format indicated at http://www.hgvs.org/mutnomen/ and refers to the DNA level.

The forward sequence achieved from genomic DNA purified from female carriers of the family showed an overlap beginning at base 37 of exon 5 (position of the adenine deleted), while on the reverse sequence the overlap was observed from the beginning of the sequence to base 37 . This is explained by the fact that carrier women have both the normal and the mutated alleles, and the presence of both alleles results in reading, by the sequencer, of two bases at the same time. When these same individuals were cloned, the deletion was clearly observed. In men, we were able to identify the deletion, both in the sequencing and cloning results.

Of the 33 subjects studied, 15 showed the mutation (45.45\%), of which 12 were women (80\%) and 3 were men (20\%) (Figure 2).

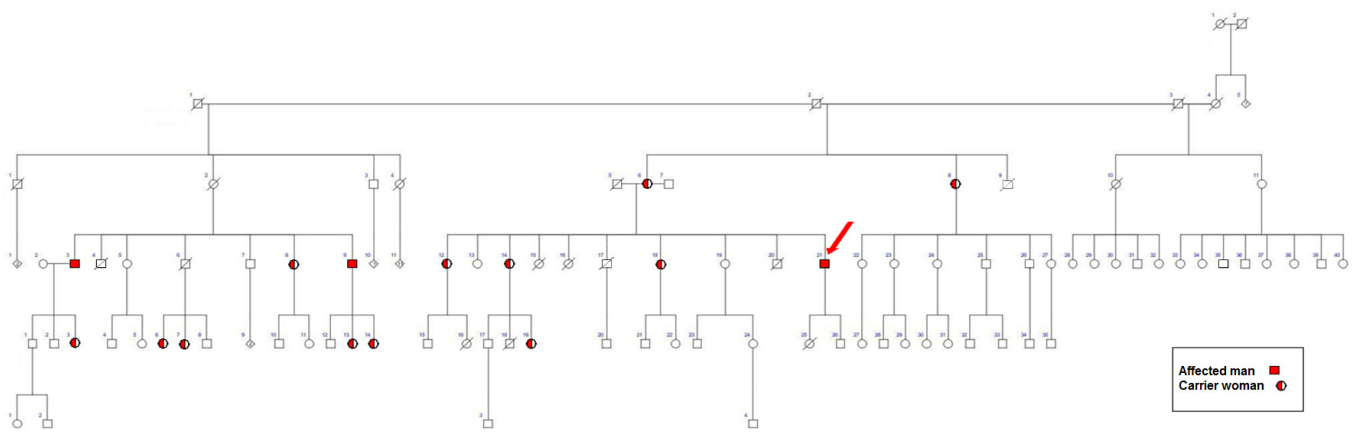

Figure 2. Pedigree of the family studied. Individuals carrying the deletion are highlighted and the proband is indicated by the arrow. There was an association between the mutation found and the X-ALD family case. Of the 33 subjects studied, 15 showed the mutation, 12 females and 3 males. Despite the fact that all of them had the same mutation, clinical manifestations varied, showing variable expression of this disease.

\section{DISCUSSION}

As of January 2010, 1065 mutations in the ABCD1 gene, of which 522 are non-recurrent mutations, have been identified and listed in the X-linked Adrenoleukodystrophy Database. They have been described for all 10 exons of the gene, and are generally infrequent and usually confined to a single family. Most of these mutations (61\%) are missense mutations, and among all the point mutations, $78 \%$ are transitions. In addition, $75 \%$ of all mutations of this gene result in the absence of ALDP activity (X-linked Adrenoleukodystrophy Database). Over $93 \%$ of patients with X-ALD inherited the mutation from their mothers and the remaining 7\% represent new mutations (Fanen et al., 1994). The only hotspot mutation described is a dinucleotide deletion in exon 5 (c.1415_1416delAG; ATG = 387, c.1801_1802delAG; p.Glu471fs) with a recurrence frequency of about $12 \%$ (Lachtermacher et al., 2000).

The alteration found in the family of this study is a novel mutation. It is important to highlight some points that indicate that this deletion is in fact the mutation causing adrenoleukodystrophy in this family. First, there is an association between the mutation and a family case of the disease, as evidenced in the pedigree (Figure 2). Second, the deletion alters a codon coding 
for a glutamate that is highly conserved in mammals, birds, fishes, amphibians, echinoderms, insects, and even fungi, as revealed by analyses performed with the BLAST tool of NCBI (http:// blast.ncbi.nlm.nih.gov/Blast.cgi) (Figure 3). In addition, the sequencing of 50 control subjects was also carried out and the deletion was not found in any of these samples. Moreover, the mutation causes a change in translation, resulting in a truncated protein that has only 556 amino acids, instead of the 745 found in the wild-type protein (http://ca.expasy.org/tools/dna.html) (Figure 3). Thus, the frame shift caused by the deletion leads to a significant change in the protein, and it is unlikely that it represents just a simple SNP. However, more than simply observing the frame shift, it is important to understand what really changes in the protein.

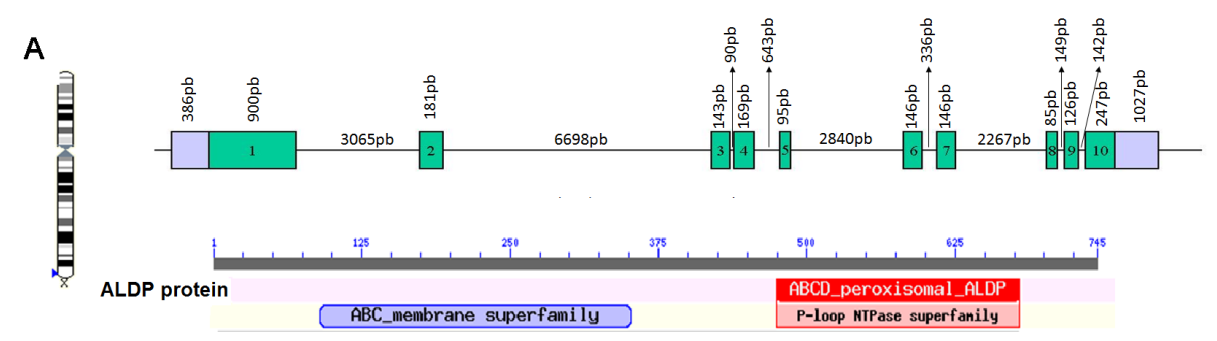

B
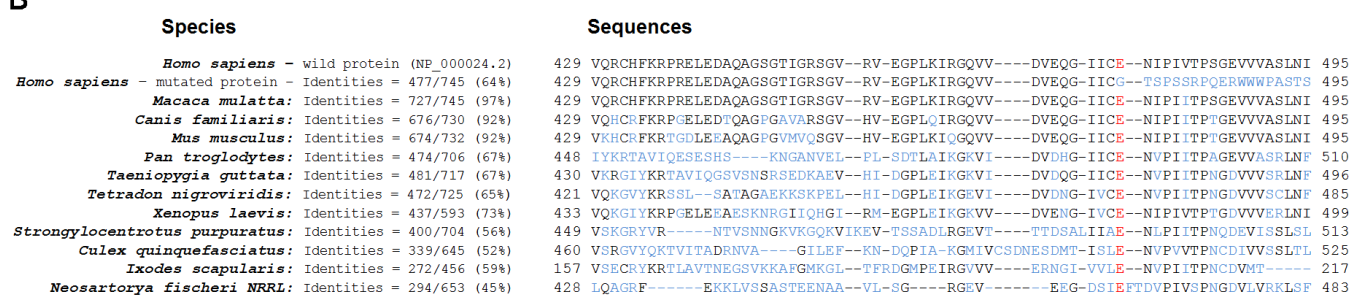

Figure 3. A. ABCD1 gene, located on the X-chromosome, consisting of 10 exons, encodes the adrenoleukodystrophy protein (ALDP) with 745 amino acids. This protein has two domains: the membrane ABC superfamily, a transmembrane domain with six helical segments, and the P-loop NTPase superfamily, an ATP-binding domain. It is observed that the latter begins shortly before the 500th amino acid of the protein. Because the mutation described in this study is an adenine deletion occurring at the 477th amino acid (glutamate), we can conclude that the mutated ALDP has no functional ATP-binding site. B. Multiple protein alignment of the amino acid partial sequence from ALDP. Comparison of the sequence of the normal protein obtained from NCBI (NP 000024.2) with the mutated protein resulting from the adenine deletion, obtained from the Translate Tool of ExPASy Proteomics Server, shows a sequence identity of $64 \%$. It can be observed from this alignment, performed by the Blastp 2.2.21+ program, using as reference the wild-type ALDP and the non-redundant protein sequences database (nr), that there is a conservation of the amino acid glutamate (E) in several species, including mammals, amphibians, fish, invertebrates, and fungi. Red indicates the preserved amino acid and blue indicates the amino acid that differentiates the sequences of the species compared.

The ALDP belongs to the superfamily of adenosine triphosphate-binding cassette transmembrane transporters ( $\mathrm{ABC}$ transporters). The molecules of this family are characterized by two highly hydrophobic domains in the amino-terminal region, each one containing six transmembrane sequences with a secondary structure in $\alpha$-helix, whose amino acid composition determines the specificity of the molecules transported (Higgins, 1992). These proteins also contain a hydrophilic sequence with two preserved adenosine triphosphate-binding cassette carboxy-terminal domains (Pan et al., 2005) involved with ATP binding and hydrolysis 
that occur during the transport process (Dean and Santis, 1994). In fact, ALDP is a half-size $\mathrm{ABC}$ transporter, and its amino terminus contains the transmembrane domain, consisting of six transmembrane segments, while the carboxy-terminal portion contains a single hydrophilic ATP-binding domain (Kemp and Wanders, 2007). However, this type of carrier must be composed of two transmembrane domains and two ATP-binding cassette domains to be functional. According to Pan et al. (2005) there are clusters of mutations described for X-ALD in the transmembrane domain $(40 \%)$ and in the adenosine triphosphate-binding cassette domain (30\%).

Considering the mutation found in this study, it was observed, from a protein-protein BLAST (blastp) (Figure 3), that ALDP produced by carriers of the deletion does not have the highly conserved ATP-binding domain (P-loop NTPase superfamily). One must, therefore, consider that this protein has an inefficient activity or even no activity at all, as it lacks the portion that provides energy for the transport function.

In the family studied, the disease manifested only during adulthood. The phenotypes of the three living affected men are distinct in relation to age of first symptoms, severity of the disease progression and predominance of symptoms, and all of them have the cerebral form, AMN and Addison's disease. Only one of the 12 women carrying the mutation showed atypical neurological manifestation, with hemiparesis and without MRI abnormalities in the brain or spinal cord, as cited by van der Knaap and Valk (2005). These distinctive phenotypes support the idea that there are other factors that modify the phenotype of X-adrenoleukodystrophy (Smith et al., 1991; Berger et al., 1994; Kok et al., 1995). The phenotypic variability of the disease can, therefore, be largely influenced by genetic and environmental factors (Pan et al., 2005). Moreover, this significant alteration, along with other similar or even more harmful alterations, leave doubt as to what the function of the ABCD1 gene really is. Nevertheless, there is no doubt that this is truly the gene linked to the disease.

\section{ACKNOWLEDGMENTS}

Research supported by Fundação de Amparo à Pesquisa do Estado de Minas Gerais (FAPEMIG) - SUS - EDT 3261-06, Brazil. We thank all members of the family studied who willingly participated in this research, and Professor Eduardo Tarazona for the availability of the Hispanic and Asian control samples.

\section{REFERENCES}

Berger J, Molzer B, Fae I and Bernheimer H (1994). X-linked adrenoleukodystrophy (ALD): a novel mutation of the ALD gene in 6 members of a family presenting with 5 different phenotypes. Biochem. Biophys. Res. Commun. 205: 1638-1643.

Bezman L, Moser AB, Raymond GV, Rinaldo P, et al. (2001). Adrenoleukodystrophy: incidence, new mutation rate, and results of extended family screening. Ann. Neurol. 49: 512-517.

Blaw ME (1970). Melanodermic Type Leucodystrophy (Adrenoleukodystropy). In: Leucodystrophies and Poliodystrophies (Vinken PJ and Bruyn GWE, eds.). North Holland Publishing, Amsterdam, 128-133.

Boehm CD, Cutting GR, Lachtermacher MB, Moser HW, et al. (1999). Accurate DNA-based diagnostic and carrier testing for X-linked adrenoleukodystrophy. Mol. Genet. Metab. 66: 128-136.

Dean M and Santis G (1994). Heterogeneity in the severity of cystic fibrosis and the role of CFTR gene mutations. Hum. Genet. 93: 364-368.

Eichler EE, Budarf ML, Rocchi M, Deaven LL, et al. (1997). Interchromosomal duplications of the adrenoleukodystrophy locus: a phenomenon of pericentromeric plasticity. Hum. Mol. Genet. 6: 991-1002.

El-Deiry SS, Naidu S, Blevins LS and Ladenson PW (1997). Assessment of adrenal function in women heterozygous for adrenoleukodystrophy. J. Clin. Endocrinol. Metab. 82: 856-860.

Genetics and Molecular Research 10 (1): 65-74 (2011)

CFUNPEC-RP www.funpecrp.com.br 
Fanen P, Guidoux S, Sarde CO, Mandel JL, et al. (1994). Identification of mutations in the putative ATP-binding domain of the adrenoleukodystrophy gene. J. Clin. Invest. 94: 516-520.

Grosko AP and Ferreira RJ (2006). Aspectos biológicos e moleculares da adrenoleucodistrofia. Arq. Ciênc. Saúde Unipar 10: 43-47.

Higgins CF (1992). ABC transporters: from microorganisms to man. Annu. Ver. Cell Biol. 8: 67-113.

Igarashi M, Schaumburg HH, Powers J, Kishmoto Y, et al. (1976). Fatty acid abnormality in adrenoleukodystrophy. $J$. Neurochem. 26: 851-860.

Jardim LB, da Silva AC, Blank D, Villanueva MM, et al. (2010). X-linked adrenoleukodystrophy: clinical course and minimal incidence in South Brazil. Brain Dev. 32: 180-190.

Kemp S and Wanders RJ (2007). X-linked adrenoleukodystrophy: very long-chain fatty acid metabolism, ABC halftransporters and the complicated route to treatment. Mol. Genet. Metab. 90: 268-276.

Kok F, Neumann S, Sarde CO, Zheng S, et al. (1995). Mutational analysis of patients with X-linked adrenoleukodystrophy. Hum. Mutat. 6: 104-115.

Korenke GC, Fuchs S, Krasemann E, Doerr HG, et al. (1996). Cerebral adrenoleukodystrophy (ALD) in only one of monozygotic twins with an identical ALD genotype. Ann. Neurol. 40: 254-257.

Lachtermacher MB, Seuanez HN, Moser AB, Moser HW, et al. (2000). Determination of 30 X-linked adrenoleukodystrophy mutations, including 15 not previously described. Hum. Mutat. 15: 348-353.

Loes DJ, Fatemi A, Melhem ER, Gupte N, et al. (2003). Analysis of MRI patterns aids prediction of progression in X-linked adrenoleukodystrophy. Neurology 61: 369-374.

Mahmood A, Dubey P, Moser HW and Moser A (2005). X-linked adrenoleukodystrophy: therapeutic approaches to distinct phenotypes. Pediatr. Transplant. 9 (Suppl 7): 55-62.

Miller SA, Dykes DD and Polesky HF (1988). A simple salting out procedure for extracting DNA from human nucleated cells. Nucleic Acids Res. 16: 1215.

Montagna G, Di Biase A, Cappa M, Melone MA, et al. (2005). Identification of seven novel mutations in ABCD1 by a DHPLC-based assay in Italian patients with X-linked adrenoleukodystrophy. Hum. Mutat. 25: 222.

Moser AB, Kreiter N, Bezman L, Lu S, et al. (1999). Plasma very long chain fatty acids in 3,000 peroxisome disease patients and 29,000 controls. Ann. Neurol. 45: 100-110.

Moser HW (2006). Therapy of X-linked adrenoleukodystrophy. NeuroRx 3: 246-253.

Moser HW and Moser AB (1996). Peroxisomal disorders: overview. Ann. N. Y. Acad. Sci. 804: 427-441.

Moser HW, Moser AB, Frayer KK, Chen W, et al. (1981). Adrenoleukodystrophy: increased plasma content of saturated very long chain fatty acids. Neurology 31 : 1241-1249.

Moser HW, Powers JM and Smith KD (1995). Adrenoleukodystrophy: molecular genetics, pathology, and Lorenzo's oil. Brain Pathol. 5: 259-266.

Moser HW, Smith KD, Watkins PA, Powers J, et al. (2001). X-linked Adrenoleukodystrophy. In: The Metabolic and Molecular Bases of Inherited Disease (Scriver CR, Beaudet AL, Sly WS and Valle D, eds.). McGraw Hill, New York, 3257-3301.

Moser HW, Mahmood A and Raymond GV (2007). X-linked adrenoleukodystrophy. Nat. Clin. Pract. Neurol. 3: 140-151.

Mosser J, Douar AM, Sarde CO, Kioschis P, et al. (1993). Putative X-linked adrenoleukodystrophy gene shares unexpected homology with ABC transporters. Nature 361: 726-730.

Pan H, Xiong H, Wu Y, Zhang YH, et al. (2005). ABCD1 gene mutations in Chinese patients with X-linked adrenoleukodystrophy. Pediatr. Neurol. 33: 114-120.

Peters C, Charnas LR, Tan Y, Ziegler RS, et al. (2004). Cerebral X-linked adrenoleukodystrophy: the international hematopoietic cell transplantation experience from 1982 to 1999. Blood 104: 881-888.

Siemerling E and Creutzfeldt HG (1923). Bronzekrankheit und sklerosierende Encephalomyelitis. Arch. Psychiatr. Nervkrankh. 68: 217-244.

Smith KD, Sack G, Beaty T, Bergin A, et al. (1991). A genetic basis for the multiple phenotypes of X-linked adrenoleukodystrophy. Am. J. Hum. Genet. 49 (Suppl): 165.

van der Knaap MS and Valk J (2005). X-linked Adrenoleukodystrophy. In: Magnetic Resonance of Myelination and Myelin Disorders (van der Knaap MS and Valk J, eds.). 3rd edn. Springer, New York, 176-190.

van Geel BM, Assies J, Weverling GJ and Barth PG (1994). Predominance of the adrenomyeloneuropathy phenotype of X-linked adrenoleukodystrophy in The Netherlands: a survey of 30 kindreds. Neurology 44: 2343-2346.

van Geel BM, Koelman JH, Barth PG and Ongerboer de Visser BW (1996). Peripheral nerve abnormalities in adrenomyeloneuropathy: a clinical and electrodiagnostic study. Neurology 46: 112-118.

van Geel BM, Bezman L, Loes DJ, Moser HW, et al. (2001). Evolution of phenotypes in adult male patients with X-linked adrenoleukodystrophy. Ann. Neurol. 49: 186-194.

van Roermund CW, Visser WF, Ijlst L, van Cruchten A, et al. (2008). The human peroxisomal ABC half transporter ALDP functions as a homodimer and accepts acyl-CoA esters. FASEB J. 22: 4201-4208.

Genetics and Molecular Research 10 (1): 65-74 (2011) 